\title{
Editorial
}

\section{A modo de invitación: una apuesta por resignificar el desarrollo en Latinoamérica}

http://doi.org/10.14718/revfinanzpolitecon.2019.11.1.1

\author{
Verel Elvira Monroy Flores*
}

Hoy en día Latinoamérica, ante la prevalencia de problemas como la pobreza, el deterioro ambiental, la vulneración de derechos o la violencia, expresa la urgencia de restaurar los debates en torno al desarrollo y plantear alternativas a este que permitan un mejor vivir. Durante el siglo XX y las primeras décadas del siglo XXI, la región se ha enfrentado a una serie de problemas económicos resultado del colonialismo y el imperialismo, a lo que se aúna la inestabilidad política y social de cada país del continente. Todo ello le ha impreso el sello de región subdesarrollada, y en respuesta a esta situación se ha originado una serie de propuestas teóricas ad hoc para plantear alternativas y soluciones a sus problemáticas particulares.

No obstante, el convencionalismo de las teorías alternativas y de las posturas clásicas no ha permitido resignificar el problema del desarrollo en Latinoamérica; es más, aunado a la instauración de los regímenes progresistas, principalmente al sur del continente, el saldo de estas gestiones ha sido adverso, pues, a pesar de que 26 países dentro del continente son clasificados como de renta media y cuatro han ascendido como naciones de ingresos altos (Bahamas, Trinidad y Tobago, Bermudas y Chile), casi el $30 \%$ de la población en la región vive bajo la línea de pobreza, mientras que el $12 \%$ lo está bajo la línea de indigencia (Programa de las Naciones Unidas para el Desarrollo [PNUD], 2016). Asimismo, el crecimiento se ha desacelerado casi a nivel generalizado y surgieron nuevamente fenómenos como la hiperinflación (principalmente en países como Argentina y Venezuela) y crisis de legitimidad (Brasil, México, Venezuela), al tiempo que el desplazamiento forzado entre 2016 y 2017 se incrementó de 436.000 personas a 457.000, afectando sobre todo a El Salvador, Colombia y México (Consejo Noruego para Refugiados, 2018).

Resultado de una experiencia de más de sesenta años de constructos en torno al desarrollo, es urgente hacer conciencia de que Latinoamérica no necesariamente requiere y del afianzamiento del orden y el progreso propios de los siglos XIX y XX, sino, más bien, enfatizar en la interconexión que subyace dentro de las esferas económica, política, sociocultural y ambiental, así como en las necesidades, capacidades y potencialidades de los seres humanos y los territorios (Monroy, 2014); en suma, es posible dotar estos elementos de consistencia teórica y formalizar las alternativas posibles al desarrollo.

* Doctorado (C) en Ciencias Sociales, Magíster en Discapacidad e Inclusión Social, Economista. Editora invitada de la revista Finanzas y Política Económica de la Universidad Católica de Colombia. Correo electrónico: verelmf1@gmail.com. (D) https://orcid.org/0000-0002-4681-1576 
En este horizonte, en el presente número de la revista Finanzas y Política Económica cada artículo aporta un poco al debate en torno al desarrollo y el crecimiento. La invitación a resignificar el desarrollo está abierta a cualquier contexto, no solo el latinoamericano; nuestra revista se constituye en un referente para abordar este tema en la región. Así, en primer lugar, Nieto y Rendón, en su artículo “¿Es la integración regional un vehículo para la convergencia? El caso de Mercosur 1990-2014", plantean un cuestionamiento sugerente: ¿es la integración regional un vehículo para la convergencia? Para resolverla, revisan el marco teórico de la integración y buscan explicaciones que justifiquen el proceso de integración en torno a esta figura, bajo el esquema de unión aduanera y su vinculación con la convergencia. Los autores concluyen que Mercosur no ha favorecido el crecimiento de los países en términos de PIB per cápita.

Por otra parte, Gyula y Siljak, investigadores del Instituto de Asuntos Exteriores y Comercio de Hungría, proponen su artículo "Economic convergence of the Western Balkans toward the EU-15", en el que demuestran que la reciente crisis financiera en la región de los Balcanes Occidentales afectó negativamente el proceso de convergencia absoluta y condicional, cuando se incluyen variables económicas como la apertura económica, la tasa de inflación y la formación bruta de capital fijo.

Simultáneamente, en "Foreign direct investment and economic growth in Jordan: An empirical investigation by the bounds test for co-integration", Oudat, Alsmadi y Alrawashdeh recopilan indicadores principalmente del Banco Mundial, a partir de los cuales se revela que los hacedores de políticas jordanos se esfuerzan por atraer más inversión extranjera directa (IED) a la economía de este país, pues ello conduce a una disminución de los obstáculos económicos, como la reducción de la tasa de desempleo y el aumento del nivel de inversión productiva.

En "EI TLC Colombia-Japón: ¿oportunidad comercial? Un análisis ex-ante", Venegas y De la Peña ponen en claro los efectos cuantitativos de una reducción arancelaria entre Colombia y Japón como consecuencia de un posible acuerdo comercial; resaltan que para algunos sectores particulares se identifican oportunidades de exportación, y señalan que los efectos comerciales son bajos para ambos países y que existen mínimos riesgos potenciales.

Por otro lado, Ramón Dangla, a través de su artículo "Reforma económica laboral vs. coyuntura económica: el impacto sobre las finanzas del fondo de garantía salarial español", evidencia que la reforma laboral del 2012 en España, adoptada bajo la influencia de la estabilidad presupuestaria, ha tenido éxito e influido notoriamente sobre las cuentas del Fondo de Garantía Salarial (FOGASA). Para ello, el autor analizó los presupuestos y buscó, mediante un modelo de regresión lineal, las variables que mejor el comportamiento de los gastos, como la evolución del PIB y otras variables económicas que tienen mayor peso que la reducción de prestaciones.

En el trabajo "Desempleo juvenil en Colombia: ¿la educación importa?", García y Castillo establecen a partir de la modelación econométrica (logit-probit) una serie de factores que influyen en la tasa de desempleo juvenil. Concluyen que hay que prestar particular atención al papel de la educación y confirman la importancia de esta para la consecución de empleos formales, pero no necesariamente en la probabilidad de estar ocupado. 
Por su parte, Rivera y Rivera, en "Crisis financieras: esta vez no es distinto", presentan una discusión sobre las principales características teóricas que tienen las diferentes tipologías de crisis financieras; afirman que un banco central está limitado para actuar contra burbujas de crédito y que los modelos macroeconómicos actuales no pueden explicar correctamente las interacciones dentro los mercados financieros. Los autores deducen además la posibilidad de que las economías emergentes en el ámbito mundial sufran crisis financiera en los meses próximos.

En el artículo "Impacto de las decisiones de política monetaria de la FED en indicadores de la economía colombiana durante el periodo 2007-2015", Parra concluye que los anuncios de política monetaria de la Reserva Federal (FED) en el periodo de análisis impactaron de manera significativa el índice COLCAP $^{1}$ y la tasa representativa del mercado (TRM), en ventanas de 3,5 y 7 días, en el $93,3 \%$ de los casos. Finalmente, en "Fundamentos conceptuales para la tasación de multas ambientales en Colombia", Redondo e Ibarra establecen una interesante discusión en torno a la tasación de multas ambientales en Colombia, a través de la cual determinan que la fórmula de tasación de multas por infracción ambiental en el país es adecuada para los procesos sancionatorios que se desarrollan.

De esta manera, la revista Finanzas y Política Económica invita a sus lectores y a sus autores a sumarse a esta tarea de resignificar el crecimiento y, sobre todo, el desarrollo de nuestros contextos. El latinoamericano es un continente que se transforma de acuerdo con las condiciones de vida de las personas y de las naciones, en regiones y realidades continuamente cambiantes en términos materiales e históricos.

\section{REFERENCIAS}

1. Banco de la República (2018). Índices del mercado bursátil colombiano. Recuperado de http://www.banrep. gov.co/es/indices-del-mercado-bursatil-colombiano

2. Consejo Noruego para Refugiados (2018). Informe mundial sobre desplazamiento interno 2018 - GRID 2018. Recuperado de http:/www.internal-displacement.org/global-report/grid2018/downloads/misc/2018-GRIDHighlights-SP.pdf

3. Monroy Flores, V. (2014). VI Congreso en Desarrollo Económico y Calidad de Vida: "Alternativas al desarrollo y buen vivir”. Recuperado de https://goo.gl/RK9S1Q

4. Programa de las Naciones Unidas para el Desarrollo (PNUD) (2016). Progreso multidimensional: bienestar más allá del ingreso [Informe Regional sobre Desarrollo Humano para América Latina y el Caribe]. Recuperado de http://www.latinamerica.undp.org/content/rblac/es/home/library/human_development/ informe-regional-sobre-desarrollo-humano-para-america-latina-y-e.html

1 "EI COLCAP es un índice de capitalización que refleja las variaciones de los precios de las acciones más líquidas de la Bolsa de Valores de Colombia (BVC)" (Banco de la República, 2018). 